\title{
Optimizing Quantum Dot Solar Concentrators with Thin Film Solar Cells
}

\author{
W.G.J.H.M. van Sark ${ }^{1, a}$, C. de Mello Donegá2,b and R.E.I. Schropp ${ }^{3, c}$ \\ ${ }^{1}$ Science Technology and Society, Copernicus Institute, Utrecht University, Heidelberglaan 2, 3584 \\ CS Utrecht, the Netherlands \\ ${ }^{2}$ Condensed Matter and Interfaces, Debye Institute for NanoMaterials Research, P.O. Box 80,000, \\ 3508 TA Utrecht, the Netherlands \\ ${ }^{3}$ Nanophotonics, Debye Institute for NanoMaterials Research, P.O. Box 80,000, 3508 TA Utrecht, \\ the Netherlands

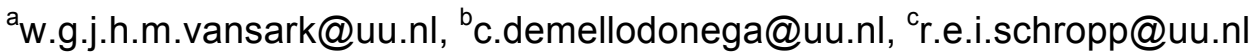

Keywords: Luminescent solar concentrator, quantum dot, thin film, solar cell.

\begin{abstract}
Quantum dots are proposed as luminescent species in luminescent solar concentrators in combination with thin film silicon solar cells. As both tuning absorption and emission properties of quantum dots is possible by adapting process conditions, as well as tuning the band gap of thin film silicon solar cells, an optimum combination is expected to exist for which the conversion efficiency of the whole device is maximum. As a first step we have employed ray-tracing modeling to determine the efficiency of a luminescent concentrator using several quantum dots and heteronanocrystals with varying Stokes' shift and absorption cross sections. A maximum efficiency of $5.9 \%$ is found for so-called Type II heteronanocrystals.
\end{abstract}

\section{Introduction}

Widespread deployment of photovoltaic (PV) technology is inhibited by cost. Lowering the cost per unit of generated power continues to be the key driver in PV research and development. Financial support is still required, e.g., by means of investment subsidies or feed-in tariffs, however, as cost is reducing, this financial support per unit of power or energy is reduced as well, until grid parity is reached. At that point, the price of electricity that a consumer is required to pay to the utility equals the one of PV, and feed-in tariff schemes are not needed anymore. Grid parity is expected to be possible within between 5-10 years for all countries in Europe.

Conversion of the incident solar spectrum to monochromatic light would greatly increase the efficiency of solar cells. Down conversion or rather down shifting was suggested in the late 1970s to be used in so-called luminescent solar concentrators (LSC), also referred to as fluorescent concentrators [1-8]. To these LSCs one or more solar cell(s) were attached. LSCs consist of a highly transparent plastic, in which luminescent species, usually organic dye molecules, are dispersed, see Fig. 1. These dyes absorb incident light and isotropically emit it at a red-shifted wavelength, with high quantum efficiency. Internal reflection ensures collection of part of the emitted light in the solar cell(s) at the side(s) of the plastic body; this holds in particular for a plastic body with high geometrical symmetry [9]. The energy of the emitted photons ideally is only somewhat larger than the band gap of the attached solar cells, to ensure near-unity conversion efficiency, and an increase in solar cell efficiency can be expected. Also, it was suggested to use a number of different organic dye molecules of which the re-emitted light was matched for optimal conversion by different solar cells. This is similar to using a stack of multiple solar cells, each sensitive to a different part of the solar spectrum. Efficiencies of $\sim 30 \%$ were expected [10,11]. 


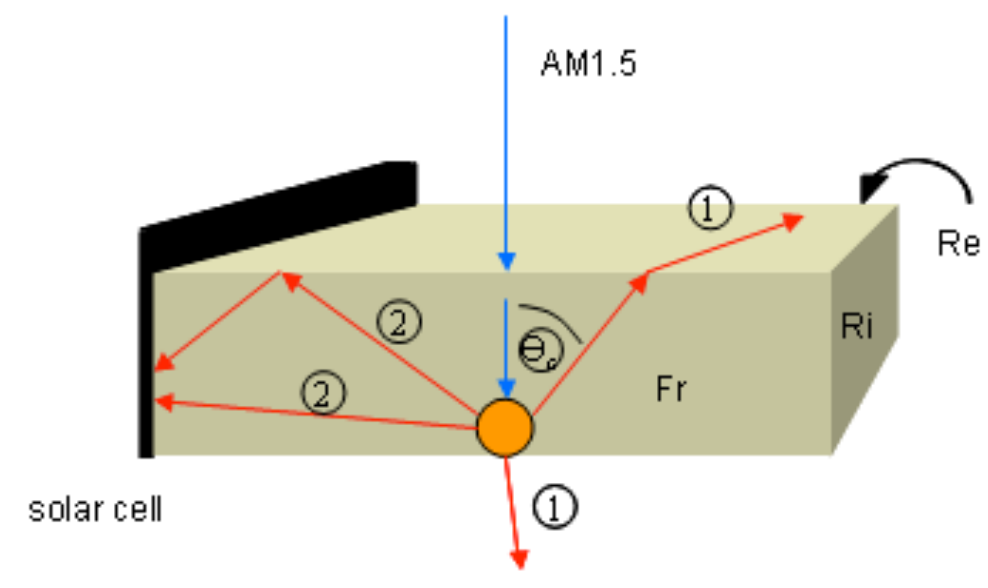

Fig. 1. Schematic 3D view of a luminescent concentrator. AM1.5 light is incident on the top. The light is absorbed by a luminescent particle. The luminescence from the particle is randomly emitted. Part of the emission falls within the escape cone (determined by the angle $\left(\theta_{c}\right)$ ) and is lost from the luminescent concentrator at the surfaces (1). The other part (2) of the luminescence is guided to the solar cell by total internal reflection [12].

Research over the past three decades has been focused on [13]: 1) absorbing all photons with wavelength $>950 \mathrm{~nm}$, and emit them red-shifted at $\sim 1000 \mathrm{~nm}$, for use with c-Si solar cells; 2) have as low as possible spectral overlap between absorption and emission spectra to minimize reabsorption losses; 3) have near unity luminescence quantum yield; 4) have low escape cone losses; 5) are stable outdoors for longer than 10 years; 6) are easy to manufacture at low cost. Much progress has occurred, which is illustrated by the recent efficiency record of $7.1 \%$ [14] for organic dyes in PMMA, as a result of a optimization study guided by modeling [12].

The present lack of NIR dyes will prohibit further increase of conversion efficiency towards the $30 \%$ limit. Here, quantum dots (QDs) or nanorods may have to be used, as their broad absorption spectrum is favorable. LSCs in which QDs are incorporated are referred to as quantum dot concentrators (QDCs) [15]. However, they should be emitting in the NIR at high quantum efficiency, larger than the present $\sim 70-80 \%$, with a large Stokes' shift. The latter would be possible by the use of type II QDs, as their Stokes' shift could be large, see Fig. 2, but presently their stability and QE are not high enough. Note that these QDs actually are heteronanocrystals (HNCs), as the core consists of CdTe and the shell of CdSe [16]. Moreover, the present Stokes's shift of $\sim 300 \mathrm{~nm}$ is too large, as a large part of solar spectrum (in the case of Fig. 2 between 600 and 900 $\mathrm{nm}$ ) is not absorbed. Stability could be improved using multishell QDs [17], while interfacial alloying can be optimized to obtain type II QDs with desired properties [18]. Such type II QDs, i.e., with Stokes' shift of 50-100 nm are presently developed, and hold promise in LSCs in combination with thin film silicon solar cells. Optimum absorption and emission properties can be tailored to match the band-gap of the used thin film cell, as band gap engineering of such cells is controllable by adjusting processing conditions [19].

As a first step towards such an optimized QDC, a modeling study is pursued in this paper. Using actual absorption and emission properties of several QDs (ranging from pure type I QDs via mixtures to a pure type II QDs), a ray-trace model [12,20] is deployed for a QDC coupled to a c-Si solar cell. 

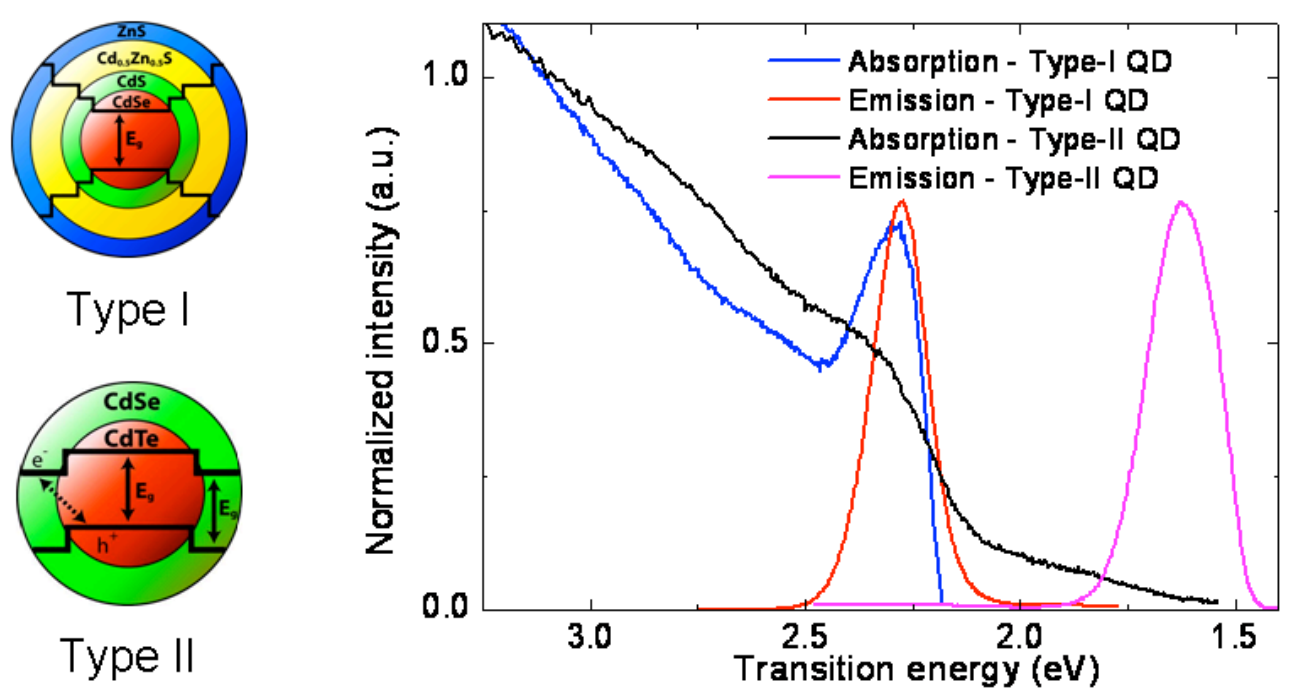

Fig. 2. Schematic representation of Type I (CdSe-ZnS) quantum dots and Type II (CdSe-CdTe) heteronanocrystals, and their respective normalized absorption and emission spectra $[18,21]$.

\section{Methodology}

Ray-trace simulations. The 3-D ray-tracing model for QDCs used here is based on standard raytracing principles. Any ray representing light of a certain wavelength travelling in a certain direction, is traced until it leaves the system, e.g., by absorption or reflection at interfaces. The model [20] applies statistical averaging of the absorption, which leads to a large reduction of computation time. The main extension to the standard ray-tracing model is the handling of the absorption and emission by the luminescent species in the QDC. The model has proven to be well able to explain experimental results on practical LSC devices of reflection and transmission measurements, as well as LSC photo response [12].

The QDCs used in the study consist of a polymethylmethacrylate (PMMA) plate (refractive index $\mathrm{n}=1.49$, absorption coefficient $1 \mathrm{~m}^{-1}$ ) in which QDs are dispersed. The dimensions of the square plate are $50 \times 50 \times 5 \mathrm{~mm}^{3}$. The bottom mirror is a Lambertian with air-gap. The internal quantum efficiency of the solar cell used for the simulation is larger than $90 \%$ for $400-1000 \mathrm{~nm}$; this c-Si cell is characterized by a short-circuit current density of $J_{s c}=40.283 \mathrm{~mA} / \mathrm{cm}^{2}$, an opencircuit voltage of $V_{o c}=0.604 \mathrm{~V}$, a fill factor of $F F=0.764$, and an efficiency of $\eta=18.59 \%$ (measured $5 \times 2.5 \mathrm{~cm}^{2}$ sized cell) [22].

The ray-trace model yields the photon fraction as a function of wavelength collected by the solar cell. The short circuit current $J_{s c}$ per cell is calculated using

$$
J_{s c}=\frac{f_{c} n_{p h} A_{F S C} q}{A_{P V}}=f_{c} n_{p h} q \frac{l}{d}
$$

where $f_{c}$ is the photon fraction per side, $n_{p h}$ the photon number density of the used incident AM1.5 spectrum $\left(\mathrm{m}^{-2} \mathrm{~s}^{-1}\right), A_{F S C}$ the area of the plate $\left(\mathrm{m}^{2}\right), A_{P V}$ the area of one cell $\left(\mathrm{m}^{2}\right)$ and $q$ the elementary charge $\left(1.6022 \times 10^{-19} \mathrm{C}\right)$. To calculate the open-circuit voltage $V_{o c}$ fill factor $F F$, and efficiency $\eta$ we use the following equations [23]:

$$
V_{o c}=\frac{k_{B} T}{q} \ln \left(\frac{J_{s c}}{J_{s}}+1\right), v_{o c}=\frac{q V_{o c}}{k_{B} T}, F F=\frac{v_{o c}-\ln \left(v_{o c}+0.72\right)}{v_{o c}+1}, \text { and } \eta=\frac{V_{o c} J_{s c} F F}{P_{i n}}
$$


with $J_{s}$ the diode saturation current density, $k_{B}$ the Boltzmann constant $\left(1.3806503 \times 10^{-23} \mathrm{~J} / \mathrm{K}\right), T$ the temperature $(\mathrm{K}), v_{o c}$ the reduced open-circuit voltage, and $P_{\text {in }}$ the incident power density.

Quantum dot characteristics. Several Type I QDs. with either CdSe $(4.3 \mathrm{~nm})$ or CdTe $(2.6 \mathrm{~nm})$ core and $\mathrm{CdTe} / \mathrm{CdSe} \mathrm{HNCs}$ with a CdTe core $(2.6 \mathrm{~nm})$ and increasing CdSe volume fraction were selected. At very high CdSe volume fractions, Type II HNCs are obtained [16]. Absorption cross sections are shown in Fig. 3 for the selected QDs and HNCs. For comparison, also the absorption cross section of two organic dyes (CRS040 and Red305) are depicted. These dyes have been used in LSC optimization studies [12]. We used quantum efficiency for QDs and HNCs of 70\%; for the Red305 dye 95\% was used.

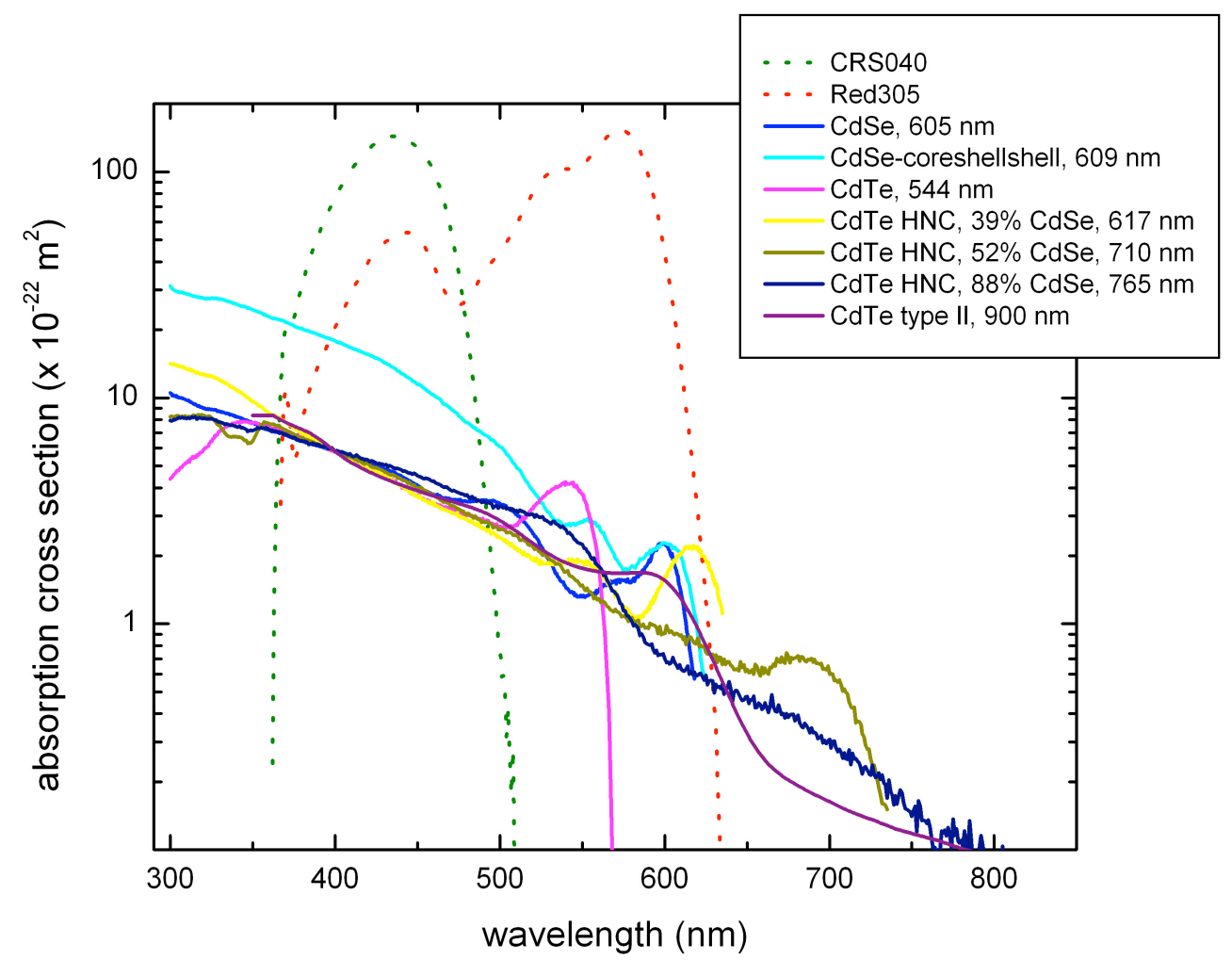

Fig. 3. Absorption cross section of $\mathrm{CdSe}$ and $\mathrm{CdTe}$ quantum dots and $\mathrm{CdTe} / \mathrm{CdSe}$ heteronanocrystals with a CdTe core $(2.6 \mathrm{~nm})$ and increasing CdSe volume fraction, compared to organic dyes CRS040 and Red305. Data from [16] and [12].

\section{Results}

We have modeled QDCs using all available data for QDs and HNCs, and have determined the conversion efficiency of the whole device. For comparison, also an LSC with the Red305 dye was modeled. All simulations have been performed as a function of QD/HNC concentration, in order to find the optimum case. Results are shown in Fig.4 and Table 1. For the LSC with the Red305 dye an optimum LSC efficiency of $5 \%$ is obtained at a concentration of $1 \times 10^{23} \mathrm{~m}^{-3}$. For all luminescent species also the lowest energy absorption peak and the integrated cross section from that peak up tp $3.1 \mathrm{eV}$, and the emission maximum are listed. For most species the Stokes' shift is small, only several nm. For the HNC with $88 \%$ CdSe the Stokes' shift is $\sim 140 \mathrm{~nm}$; the largest Stokes' shift is $315 \mathrm{~nm}$ for the $\mathrm{CdTe} / \mathrm{CdSe} \mathrm{HNC}$. For all QDs and HNCs the wavelength-dependent absorption cross sections are similar. The integrated cross section depends on the position of the lowest-energy absorption peak and therefore differs for the samples. Note that the CdSe/ZnS core shell QD has a 5-10 times larger cross section between 300-500 nm compared to other QDs and HNCs, albeit that the cross section at the lowest-energy absorption peak is about equal to HNCs with this peak at about the same position. 
The LSC/QDC efficiency clearly depends on concentration of the luminescent species in the LSC/QDC. For the QDs and HNCs we observe a maximum at a certain concentration, which depends on the total cross section and the emission wavelength of the particular QD/HNC. In case of the CdSe core shell QD, the concentration in the QDC at which the QDC efficiency is maximum is nearly an order of magnitude smaller compared to other $\mathrm{QD} / \mathrm{HNCs}$, which is due to the much higher total absorption cross section.

We also observe that the larger the emission wavelength, the higher the QDC efficiency. This is due to the larger part of the solar spectrum that is absorbed. Note, that the highest QDC efficiency is obtained for the HNC for which the absorption cross section is zero at wavelengths larger than 800 $\mathrm{nm}$. This shows also that self-absorption leads to lowering of the QDC efficiency.

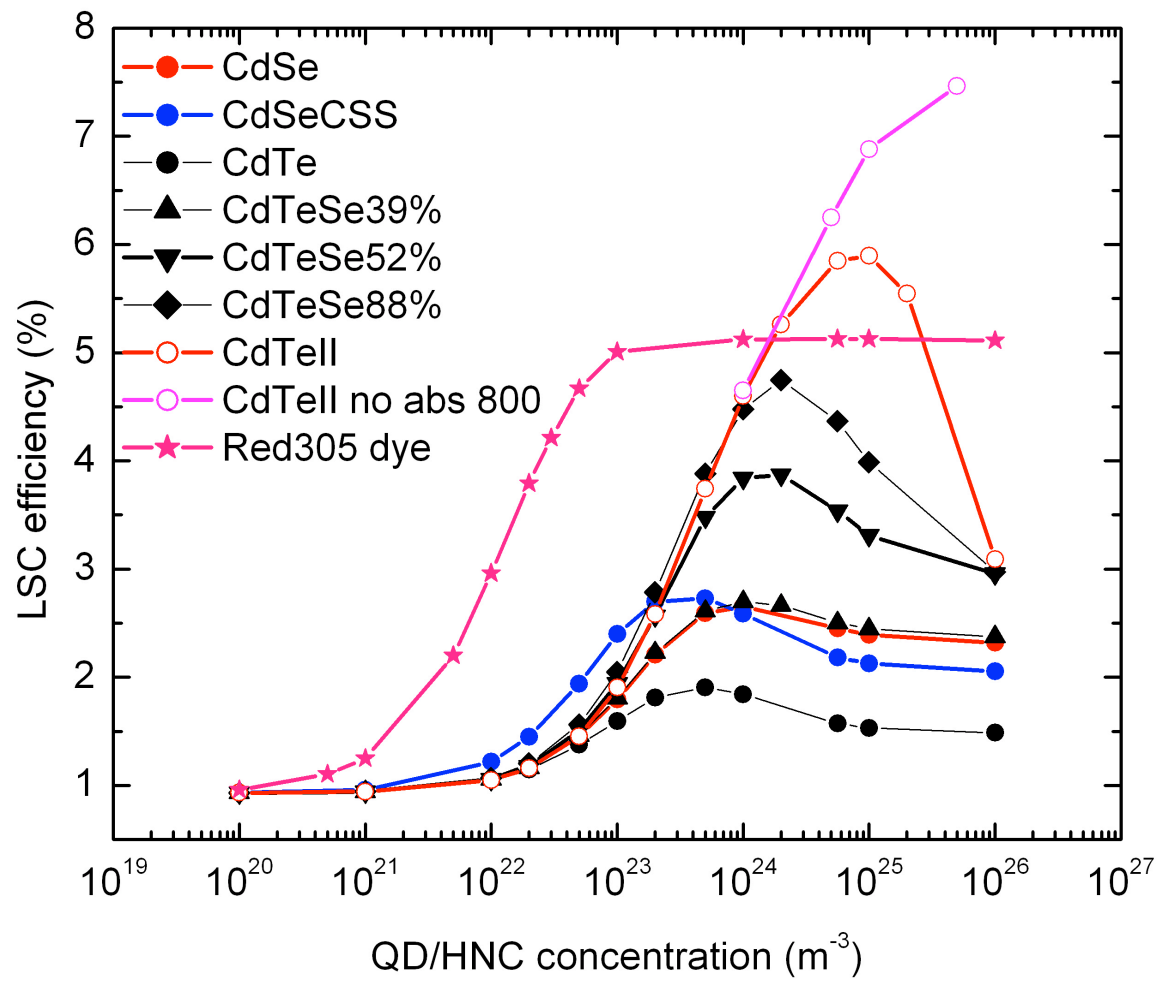

Fig. 4. LSC/QDC efficiency as a function of dye/QD/HNC concentration for all selected species, see also Table 1.

Table 1. Properties of LSC/QDCs for different luminescent species.

\begin{tabular}{cccccc}
\hline $\begin{array}{c}\text { Luminescent } \\
\text { species }\end{array}$ & $\begin{array}{c}\text { Lowest- } \\
\text { energy } \\
\text { absorption } \\
{[\mathrm{nm}]}\end{array}$ & $\begin{array}{c}\text { Integrated } \\
\text { cross section } \\
\text { up to } 3.1 \mathrm{eV} \\
{\left[\mathrm{m}^{2}\right]}\end{array}$ & $\begin{array}{c}\text { Emission } \\
\text { maximum } \\
{[\mathrm{nm}]}\end{array}$ & $\begin{array}{c}\text { Concentration } \\
\text { in LSC/QDC } \\
{\left[\mathrm{m}^{-3}\right]}\end{array}$ & $\begin{array}{c}\text { LSC/QDC } \\
\text { maximum } \\
\text { efficiency } \\
{[\%]}\end{array}$ \\
\hline Red305 dye & 572 & $\sim 10^{-21}$ & & $1 \times 10^{23}$ & 5.00 \\
CdSe core & 596 & $1.8 \times 10^{-19}$ & 605 & $1 \mathrm{e}^{24}$ & 2.65 \\
CdSe core/shell & 599 & $5.6 \times 10^{-19}$ & 609 & $5 \mathrm{e}^{23}$ & 2.73 \\
CdTe core & 540 & - & 544 & $5 \mathrm{e}^{23}$ & 1.91 \\
CdTe/39\% CdSe & 615 & $0.8 \times 10^{-19}$ & 617 & $1 \mathrm{e}^{24}$ & 2.70 \\
CdTe/52\% CdSe & 701 & $1.0 \times 10^{-19}$ & 710 & $2 \mathrm{e}^{24}$ & 3.87 \\
CdTe/88\% CdSe & 525 & $4.4 \times 10^{-19}$ & 765 & $2 \mathrm{e}^{24}$ & 4.75 \\
CdTe/CdSe & 585 & - & 900 & $1 \mathrm{e}^{25}$ & 5.90 \\
CdTe/CdSe, no & 585 & - & 900 & $5 \mathrm{e}^{25}$ & 7.46 \\
absorption & & & & &
\end{tabular}




\section{Conclusion}

We have determined QDC efficiency for different QDs and HNCs by varying the concentration of these species in the QDC by employing ray-trace modeling. A maximum QDC efficiency is found for Type II HNCs of 5.9\%. Total absorption cross section should be enhanced, which is possible by capping the HNCs with a proper shell, alike the CdTe/ZnS core shell QDs. The QDC with Type II HNCs outperform the LSC with the Red305 dye. This is very promising, as the present quality HNC is not yet optimized. Therefore, a QDC with $10 \%$ efficiency is within reach.

\section{References}

[1] J.S. Batchelder, A.H. Zewail, T. Cole: Appl Opt 18 (1979) p. 3090

[2] J.S. Batchelder, A.H. Zewail, T. Cole: Appl Opt 20 (1981) p. 3733

[3] R.L. Garwin: Rev Sci Instrum 31 (1960) p. 1010

[4] A. Goetzberger, W. Greubel: Appl Phys 14 (1977) p. 123

[5] A.M. Hermann: Sol Energy 29 (1982) p. 323

[6] C.F. Rapp, N.L. Boling, in: Proceedings 13th IEEE Photovoltaic Specialists Conference, IEEE, New York, NY (1978) p. 690

[7] R. Reisfeld, C.K. Jorgensen: Structure and Bonding 49 (1982) p. 1

[8] W.H. Weber, J. Lambe: Appl Opt 15 (1976) p. 2299

[9] W.A. Shurcliff, R.C. Jones; J Opt Soc Am 39 (1949) p. 912

[10]G. Smestad, H. Ries, R. Winston, E. Yablonovitch: Sol Energy Mater 21 (1990) p. 99

[11]E. Yablonovitch: J Opt Soc Am 70 (1980) p. 1362

[12]W.G.J.H.M. Van Sark, K.W.J. Barnham, L.H. Slooff, et al.: Opt Exp 16 (2008) p. 21773

[13]B.C. Rowan, L.R. Wilson, B.S. Richards: IEEE J Sel Topics in Quant Electr 14 (2008) p. 1312

[14] L.H. Slooff, E.E. Bende, A.R. Burgers, et al.: phys stat sol (RRL) 2 (2008) p. 257-259

[15] A.J. Chatten, K.W.J. Barnham, B.F. Buxton, et al.: Semiconductors 38 (2004) p. 909

[16]C. De Mello Donegá: Phys Rev B 81 (2010) p. 165303

[17]R. Koole, M. Van Schooneveld, J. Hilhorst, et al.: Chem Mat 20 (2008) p. 2503

[18]P.T.K. Chin, C. De Mello Donegá, S.S. Van Bavel, et al.: J Am Chem Soc 129 (2007) p. 14880

[19]R.E.I. Schropp, M. Zeman: Amorphous and Microcrystalline Silicon Solar Cells: Modeling, Materials, and Device Technology (Kluwer Academic, Boston, MA, USA, 1998).

[20]A.R. Burgers, L.H. Slooff, R. Kinderman, et al., in: Proceedings of Twentieth European Photovoltaic Solar Energy Conference, WIP, Munich, Germany (2005) p. 394

[21] W.J.M. Mulder, G.J. Strijkers, R. Koole, et al., in: Nanoparticles in Biomedical Imaging: Emerging Technologies and Applications, edited by J.W.M. Bulte, M. Modo, Springer, New York, NY, USA, 2007.

[22]E.E. Bende, L.H. Slooff, A.R. Burgers, et al., in: Proceedings of Twentythird European Photovoltaic Solar Energy Conference, WIP, Munich, Germany (2008) p. 461

[23]M.A. Green: Solar Cells; Operating Principles, Technology and Systems Application (Prentice-Hall, Englewood Cliffs, NJ, USA, 1982). 


\section{5th FORUM ON NEW MATERIALS PART C}

10.4028/www.scientific.net/AST.74

\section{Optimizing Quantum Dot Solar Concentrators with Thin Film Solar Cells}

10.4028/www.scientific.net/AST.74.176

\section{DOI References}

[1] J.S. Batchelder, A.H. Zewail, T. Cole: Appl Opt 18 (1979) p. 3090

10.1364/AO.18.003090

[2] J.S. Batchelder, A.H. Zewail, T. Cole: Appl Opt 20 (1981) p. 3733

10.1364/AO.20.003733

[5] A.M. Hermann: Sol Energy 29 (1982) p. 323

10.1080/713820849

[7] R. Reisfeld, C.K. Jorgensen: Structure and Bonding 49 (1982) p. 1

10.1021/ja00366a001

[8] W.H. Weber, J. Lambe: Appl Opt 15 (1976) p. 2299

10.1364/AO.15.002299

[9] W.A. Shurcliff, R.C. Jones; J Opt Soc Am 39 (1949) p. 912

10.1364/JOSA.39.000072

[10] G. Smestad, H. Ries, R. Winston, E. Yablonovitch: Sol Energy Mater 21 (1990) p. 99

10.1016/0165-1633(90)90058-9

[12] W.G.J.H.M. Van Sark, K.W.J. Barnham, L.H. Slooff, et al.: Opt Exp 16 (2008) p. 21773

10.1364/OE.16.021773

[13] B.C. Rowan, L.R. Wilson, B.S. Richards: IEE J Sel Topics in Quant Electr 14 (2008) p. 1312

10.1109/JSTQE.2008.920282

[15] A.J. Chatten, K.W.J. Barnham, B.F. Buxton, et al.: Semiconductors 38 (2004) p. 909

$10.1134 / 1.1787111$

[16] C. De Melo Donegá: Phys Rev B 81 (2010) p. 165303

10.1103/PhysRevB.81.199901

[17] R. Koole, M. Van Schooneveld, J. Hilhorst, et al.: Chem Mat 20 (2008) p. 2503

$10.1021 / \mathrm{nl} 801596 \mathrm{a}$

[18] P.T.K. Chin, C. De Melo Donegá, S.S. Van Bavel, et al.: J Am Chem Soc 129 (2007) p. 14880 $10.1021 / \mathrm{ja} 0738071$ 